\title{
Social preferences, accountability, and wage bargaining
}

\author{
Martin G. Kocher ${ }^{\#}$, Odile Poulsen ${ }^{+}$, and Daniel J. Zizzo ${ }^{\S}$
}

\begin{abstract}
We experimentally test preferences for employment in a collective wage bargaining situation with heterogeneous workers. We vary the size of the union and introduce a treatment mechanism transforming the voting game into an individual allocation task. Our results show that highly productive workers do not take employment of low productive workers into account when making wage proposals, regardless of whether only union members determine the wage or all workers. The level of pro-social preferences is small in the voting game, but it increases if the game becomes an individual allocation task. We interpret this as an accountability effect.
\end{abstract}

Keywords: social preferences, wage bargaining, accountability, collective decision making. JEL classification: C91, C92, D71, J51, J52.

\footnotetext{
${ }^{\#}$ University of Munich, Queensland University of Technology, Brisbane, and University of Gothenburg. e-mail: martin.kocher@1rz.uni-muenchen.de.

${ }^{+}$CBESS and School of Economics, University of East Anglia. e-mail: o.poulsen@uea.ac.uk.

${ }^{\S}$ Business School, Newcastle University. e-mail: daniel.zizzo@newcastle.ac.uk.
} 


\section{Introduction}

Models of wage bargaining often assume that unions have an objective function with two elements: wages and employment (Farber, 1978; MacDonald and Solow, 1981; Grossman, 1983; Blair and Crawford, 1984). Hence, they implicitly adopt the conjecture that union members or the union leadership have other-regarding or social preferences (Rabin, 1993; Fehr and Schmidt, 1999, Bolton and Ockenfels, 2000; Dufwenberg and Kirchsteiger, 2004; Falk and Fischbacher, 2006) for those non-union members who are non-employed or those who would have to fear unemployment in case of rising wages. In contrast, insider-outsider models of wage bargaining (Linbeck and Snower, 1989) are based on the premise of discrimination between insiders (union members) and outsiders (not members of the union).

In this paper, we assess the extent of preferences for employment in an abstract collective wage bargaining situation with heterogeneous workers. A laboratory experiment might allow inferring underlying preferences better than data from the field that may be contaminated by factors that are very hard to control for, such as the organization of and decision making procedures within a union, inter-temporal aspects of wage setting, unobserved incentives, or objectives of union members, and so on. We view our results as complementary to findings based on field data of union wage bargaining behavior. We are not aware of any other laboratory or field experiment that addresses the question of to what extent employment is taken into account in collective wage bargaining. Having said that, it is clear that a laboratory setup cannot capture the complexity of real-world wage bargaining. On the contrary, it should not in order to maintain as much control as possible over the incentive effects present under specified conditions. We discuss the limits of our results in terms of external validity in greater detail in the discussion section.

In our experiment we set up a stylized labor market with five heterogeneously productive workers, and we vary the number of union members exogenously. In one treatment, all workers are union members that decide on the joint wage level, and in another treatment three out of five (the three most productive workers) are union members. We choose the three most productive workers to be union members to maximize the potential conflict among workers in our setup, without implicating that such a union membership is most realistic. Workers face a (fictitious) firm that bases its employment decision deterministically on the wage rate, and the employment schedule contingent on the wage is 
common knowledge. The decision making process within the union is captured by a median voting mechanism, i.e. the median wage proposal of the workers who are eligible to vote (five or three) determines the actual wage and, consequently, the employment level. In order to make wage proposals of all union members fully incentive compatible and not only the proposal of the median voter, there is a chance in our experiment that one of the five or three individual wage proposal becomes directly implemented. More precisely, with probability $q$ the median voting mechanism becomes implemented, and with probability $(1-q)$, the individual proposal is relevant. With $q=0$ the problem reduces to an individual allocation task akin to a dictator game (Kahneman et al., 1986; Forsythe et al., 1994) ${ }^{1}$ but still with a well-defined labor market frame. With $q=1$ the median voter's preference will be implemented with certainty, but sincere voting is not the only equilibrium anymore. In the experiment we implement between-subject treatments with $q=1, q=0.8, q=0.2, q=0$ (and the dictator knows her dictator role before taking the decision; denoted EX ANTE), and $q=0$ (with the dictator implementing her decision before she knows to be decisive; denoted EX POST). The two dimensions (number of voters and $q$ ) span up a $2 \times 5$ factorial experimental design.

Our results indicate that proposals in the main treatments with a low level of $q$ are very close to the selfish benchmark. Highly productive workers do not take employment of low productive workers into account when they make their wage proposals. Interestingly, there is no significant difference between the insider-outsider treatment (with three voters) and the all-workers treatment (with all five workers voting).

Several explanations for the low level of social preferences - when compared to results from more general allocation games (Charness and Rabin, 2002; Engelmann and Strobel, 2004) and to results from the dictator game (Kahneman et al., 1986; Forsythe et al., 1994; Eckel and Grossman, 1996; List, 2007; Bardsley, 2008) - are conceivable.

One possible explanation is the framing of our decision making situation as the decision making problem of a union. However, most research on social distance (Hoffman et al., 1996; Bohnet and Frey, 1999) and social identity (Tajfel et al., 1971; Charness et al., 2007; Chen

\footnotetext{
${ }^{1}$ The standard dictator "game" is a two-person allocation task in which one person (the "dictator") receives a positive endowment and can transfer any amount between zero and the endowment to a powerless recipient.
} 
and Li, 2009; Hargreaves Heap and Zizzo, 2009; Sutter, 2009) in the realm of other-regarding preferences would indicate that our framing should, if anything, discriminate in favor of the in-group (union) members, e.g. by amplifying other-regarding behavior towards other union members. In other words, the minimal group paradigm could be applicable in our setup when union members perceive themselves as part of one group, because the social distance between union members would be decreased. As a consequence, union members should tend to take other union members' employment into account in the wage setting, and one would expect a treatment difference between the insider-outsider and the all-workers treatments. Even if ingroup favoritism were not to work in the direction of positive discrimination towards in-group members, but rather in terms of negative discrimination, we should observe a difference in behavior between these two treatments. However, such reasoning is not borne out by the data from our experiment.

A second explanation coming from research on group decision making in economics and social psychology is also be plausible in our context. Group membership leads individuals to more selfish decisions if they cannot be held accountable ${ }^{2}$ individually for their choices (Bornstein and Yaniv, 1998; Kugler et al., 2007; Luhan et al., 2009; Balafoutas et al., 2014). Group members have the possibility to "hide" behind others because they are non-identifiable (e.g., Insko et al., 1987, 1988; Güth et al., 1996; Abbink and Herrmann, 2011). The social demands or moral costs of the decision problem are therefore reduced (Ellingsen and Johannesson, 2008; Zizzo, 2010; Abbink and Herrman, 2011). Whereas the majority of research has been conducted with groups in which group members can interact directly (through a real-time chat or face-to-face communication), our setup does not allow for a group interaction beyond the voting mechanism that determines final wages. ${ }^{3}$

The variation in $q$ in our experiment can give us some guidance on to what extent the feeling of accountability of single group members might influence other-regarding

\footnotetext{
${ }^{2}$ For accountability research in the context of risky decision making see Pahlke et al. (2011) and Vieider
} (2011). The term "moral wiggle room" has also been used to describe decisions in which one finds an easy excuse for a selfish decision (Dana et al., 2007).

${ }^{3}$ This might itself have an effect on behavior, but we are not aware of any study that alters the level of interaction within a group systematically (see also Kocher and Sutter, 2007). For surveys, see Charness and Sutter (2012) and Kugler et al. (2012). 
preferences, i.e. the concern for overall employment. In general, a $q$ bounded away from $q=$ 0.5 should increase other-regarding preferences for decisive voters. In particular $q=0$ and $q=$ 1 should increase responsibility, because in the former case the median voter will be decisive with certainty (assuming sincere voting) and in the latter the dictator will be decisive. Hence in both cases, it is a single person that determines the wage and the employment level with certainty. Our data only partly confirms this hypothesis. Only if $q$ goes down to zero, we observe the expected effect of taking other workers into account, interpreted as accountability in our setup. It is important to stress the methodological contribution that comes in passing with our variation in $q$. In a between-subject design we gradually transform a voting game into an individual allocation task, presumably increasing the perceived accountability of participants in the laboratory. This is done without changing the basic setup and instructions of the decision making problem at hand. It is important to add that we do not introduce any kind of formal accountability vis-à-vis another individual in our experiment. Hence, strictly speaking, decision makers are only accountable to themselves, and one might prefer the term "guilt" instead of "accountability" in that case. We do not take a stance here but henceforth stick to the term "accountability", henceforth, when describing the effects of one's degree of influence on the final decision.

Our study provides evidence for the extent to which productive workers take the employment decision of firms and, consequently, the outcome of less productive workers into account. Our stylized setting abstracts from several important features of collective wage bargaining in the real world, but it shows that collective decisions might do a poorer job in taking the least productive into account than individual (dictator) decisions. Put differently, our results indicate that there is what we label an accountability effect: increasing the level of individual accountability in allocation decisions has the potential to increase the importance of other-regarding concerns.

Section 2 introduces the details of our experimental design and provides theoretical hypothesis. In Section 3 we present the experimental results, first on an aggregate level, focusing on treatment differences, and then on the basis of a regression analysis. Section 4 discusses our findings and concludes the paper. 


\section{Experimental design and theoretical predictions}

\subsection{Experimental design of the main part}

The main part of the experiment introduced groups consisting of five randomly assembled participants that we referred to as workers in the experimental instructions (see the online appendix for a specimen). Workers are heterogeneous with regard to their productivity; in the experiment we told participants that there were different types (type 1 to type 5, with type 1 being most productive) for which different wage ranges would allow the firm to employ them. Type 1 would be employed for every permissible wage, type 2 for a smaller wage range starting below the maximum wage, and so on. Details are given in Table 1.

Depending on the treatment, either all five (all-workers treatment; denomination INS in the following) or only the three most productive workers (insider-outsider treatment; INSOUT) were eligible to determine the wage level. In the former case there are no outsiders on the market, in the latter case there are two outsiders, and our design assigns the roles exogenously. ${ }^{4}$ More specifically, the more productive workers are always insiders in our experiment, in order to maximize the potential conflict among workers. The wage level determines the number of employed workers (see Table 1). All employed workers earn the wage, and unemployed worker earn zero.

(Insert Table 1 about here.)

The voting procedure to determine the wage is as simple as possible: the median wage proposal of the eligible workers out of the permissible wage range, $w \in[1,100]$, was implemented. As the second treatment variable we vary the probability $q$ with which the median proposal out of the proposals of the union members would become implemented instead of a randomly selected individual proposal from the set of the union members (with probability $1-q$ ). The variable $q$ is intended to adjust the level of accountability, and it makes sure that, with $q<1$, not only the proposal of the median proposer is fully incentivecompatible. The variable $q$ is set at 1, 0.8, 0.2 and 0 in different treatments of our experiment.

\footnotetext{
${ }^{4}$ An assignment according to the performance in a task would most likely reinforce our results regarding selfish behavior, because participants would perceive their position as earned rather than just assigned.
} 
The uncertainty coming from $q$ is resolved after making a wage proposal in the treatments with $q=0.8$ and $q=0.2$. In the treatments with $q=0$, we implement one treatment in which participants in the experiment learn only ex post whether one is the "dictator" in determining the wage (denoted EX-POST), and one in which the "dictator" knows it already before determining the wage (EX-ANTE). The latter treatment further increases accountability. Treatments with $q=1$ implement the median voter's preference with certainty. This adds additional voting equilibria, but under sincere voting it might also increase feelings of accountability. Table 2 summarizes the conditions applied in our experiment, and Figure 1 gives a graphical overview. The treatment variation is implemented between experimental subjects. No experimental participant experienced more than treatment.

The wage determination game is repeated ten times. Types and groups of workers remain constant over these ten periods. ${ }^{5}$ At the end of each period, the common wage is announced and everybody sees whether he or she is employed or not. Workers of type 4 and type 5 in the INSOUT treatments also receive this information, but they cannot submit a wage proposal. Individual proposals are not revealed, but workers learn whether it was the median proposal that was implemented or a randomly chosen proposal of the eligible workers (if applicable). In the EX-ANTE treatments, we asked those workers who knew that they were not going to determine the actual wage level to provide us with the wage level that they would have chosen, had they been selected as the dictator. These choices are not incentivized.

\subsection{Theoretical framework and hypotheses}

Following McDonald and Solow (1981), we describe a model of wage bargaining with nonlinear preferences for union members. We assume that there are five workers, each indexed by subscript $i, i=1,2,3,4,5$. Workers are ranked in terms of their productivity level, $Q_{i}$, as follows: $Q_{1}>Q_{2}>Q_{3}>Q_{4}>Q_{5}$. There are no costs associated with effort. A worker is employed if $Q_{i} \geq w$, the wage offered by the firm. In the first version of our model, only the three most productive workers vote. In the second version, all five workers vote. The voting procedure is identical to the one outlined in Section 2.1. We consider $q=0.8$ here, but the extension to other values of $q$ is immediate. In other words, in our theoretical setting the

\footnotetext{
${ }^{5}$ For reasons of comparability to experiments planned in the future, we decided to frame the ten decisions as five periods, each consisting of two identical stages, in the experimental instructions.
} 
median wage proposal out of the permissible wage range, $w \in[1,100]$, is implemented with an eighty percent probability. For the remaining twenty percent of the time, one of the wages submitted by workers 1,2 , or 3 in treatment INSOUT or 1, 2, 3, 4, or 5 in treatment INS is randomly chosen as the relevant wage.

\subsubsection{Insider-outsider model: Only workers 1,2 , and 3 vote}

We assume that the three most productive workers form a union and vote for the uniform wage that each employed worker receives. Once the wage has been chosen, each worker receives the chosen wage. Non-employment occurs if $\mathrm{w}>Q_{i}$.

Assume that preferences over employment and wages for each union member are given by:

$$
U_{i}=\left\{\begin{array}{c}
w^{\lambda}, \text { if } w \leq Q_{i} \quad \lambda \geq 0 \\
L^{\lambda}, \text { if } w>Q_{i}
\end{array}\right.
$$

where $\lambda$ represents the utility weight that each worker puts on the aggregate employment level, $L$. We assume that $\lambda$ is the same for all workers; allowing for individual differences in the parameter is a straightforward extension.

The productivities (we often refer to them as "outputs") used in our laboratory experiment are $\mathrm{Q}_{1}=100, \mathrm{Q}_{2}=50, \mathrm{Q}_{3}=33, \mathrm{Q}_{4}=25$, and $\mathrm{Q}_{5}=20{ }^{6}$

Proposition 1: Fix a value of $\lambda \geq 0$. Then:

- If $0 \leq \lambda<1$, the unique Nash equilibrium is $\left(w_{1}, w_{2}, w_{3}\right)=\left(Q_{1}, Q_{2}, Q_{3}\right)$.

- If $\lambda=1$, there are multiple Nash equilibria.

- If $\lambda>1$, the unique Nash equilibrium is $\left(w_{1}, w_{2}, w_{3}\right)=\left(Q_{5}, Q_{5}, Q_{5}\right)$.

Proof: See the Appendix.

${ }^{6}$ In order to simplify the analysis we assume that all employment and wages levels in the utility function are multiple of 100 . Hence, we set $Q_{3}=100 / 3($ instead of 33). 
The proposition shows that when $\lambda$ is low $(\lambda<1)$, i.e. when workers put a lower weight on employment levels than they put on the wage levels, workers vote for the highest possible wage that would maximize their earnings. As a result, the employment level is low. When $\lambda>1$, workers put more weight on employment levels than they put on their wage levels. As a result all workers are willing to accept a wage cut to help other workers get a job. All workers then vote for the wage that is compatible with full employment.

\subsubsection{All five workers vote}

We now consider the case where all five workers submit a wage proposal. This turns out to be a straightforward generalization of the analysis in the previous section.

Proposition 2: For each value of $\lambda \geq 0$, there is a unique Nash equilibrium:

- If $0 \leq \lambda<1$, the unique Nash equilibrium is $\left(w_{1}, w_{2}, w_{3}, w_{4}, w_{5}\right)=\left(Q_{1}, Q_{2}, Q_{3}, Q_{4}, Q_{5}\right)$.

- If $\lambda=1$, there are multiple Nash equilibria.

If $\lambda>1$, the unique Nash equilibrium is $\left(w_{1}, w_{2}, w_{3}, w_{4}, w_{5}\right)=\left(Q_{5}, Q_{5}, Q_{5}, Q_{5}, Q_{5}\right)$.

\section{Proof: See the Appendix}

The result extends the result in Proposition 1 to the case where five workers (instead of three) vote on the wage level. Again when $\lambda$ is low $(\lambda<1)$, i.e. when workers put a lower weight on employment levels than they put on the wage levels, the employment level is low as workers vote for a high wage, and vice versa.

\subsubsection{Discussion and implications of the theoretical results}

Our results of course depend on the choice of the specific form of nonlinear preferences and productivities chosen for the experiment. With different preferences, and the same productivities, or the same utility and different productivities, there would be different Nash equilibria. However the qualitative conclusions for a high (low) $\lambda$ would be the same: a high $\lambda$ implies that workers care more about other workers and would be more willing to accept wage cuts in order to help workers that are less productive than themselves. 
The first prediction from the model is that wage proposals are the same when union membership is restricted to three workers and when all five workers vote. In both cases, a low $\lambda$ implies that workers vote for the highest feasible wage and low employment, whereas a high $\lambda$ guarantees that workers are willing to accept wage cuts in order to help other workers get a job. Naturally, the resulting wages are expected to be different because of the median voter scheme.

The second prediction comes from a simple fact: it is more expensive for more productive types to help workers who are less productive. Worker 1 must accept a wage cut of 50 points in order to help worker 2 get a job, whereas worker 4 must only accept a wage cut of 5 points to help worker 5 get a job. Although our model predicts bang-bang solutions with either full selfishness or full employment, our behavioral expectation is that more productive workers are less likely to go down to the next wage level that increases employment. Our theoretical result is implied by the specific functional form of the utility function and the assumption of uniform $\lambda$ across workers, and other assumptions would yield different predictions.

The third prediction is that more pro-social workers, i.e. workers with higher $\lambda$ in our model, perhaps because of altruism or inequality aversion, are more likely to propose lower wages.

Finally, we note that, because votes in our model reveal the worker's true preferences, it would not make a difference to their proposals whether, instead of having the setup considered in this model, we had a unilateral determination of the wage by one of the workers. It will be handy to refer to this observation as a fourth prediction, though of course not one explicitly made within the model itself. The accountability effect referred to in the introduction would, of course, imply a direct violation of this fourth prediction.

\subsection{Experimental procedure}

The computer-based experiment was conducted at the experimental laboratory MELESSA of the University of Munich in 2011 and 2016, using the experimental software z-Tree (Fischbacher, 2007) and the organizational software ORSEE (Greiner, 2015). 520 students from all disciplines participated in 26 sessions, each with 20 participants. Approximately $61 \%$ of participants were female. Sessions lasted a bit more than an hour, and the average payoff was 15.55 euro, including a show-up fee of 4 euro. 
Upon arrival, experimental participants were seated in separate cubicles. Each session started with instructions for the main part of the experiment (described in detail in Section 2.1). At this stage it was made clear that there would be additional parts of the experiments, but that the instructions for these parts would only be handed out after the completion of the current part. It was also stressed to participants that decisions in one part would be completely unrelated to those in the other parts. Participants received written instructions (see the online appendix), which were read aloud to ensure common knowledge of them. Everybody had the opportunity to ask questions in private.

We implemented a random lottery mechanism (e.g., Starmer and Sugden, 1991), paying only one out of the ten periods in the first part of the experiment. Such a payment scheme avoids monetary complementarities (e.g., wealth effects) between periods that are supposed theoretically to be completely independent. The payoff-relevant period was randomly selected at the end of the experiment. The conversion rate for experimental points into euro (1 experimental point equals 0.25 euro) was clearly stated in the instructions. At the end of each period, every worker was informed about the chosen wage level within the group of five workers (and whether it was the median or a randomly chosen proposal) and about the income of all workers in his or her group. Individual proposals of other workers were never revealed.

Upon completion of the main part of the experiment participants received instructions for the second part that were again read aloud. Remaining questions were only allowed to be asked privately, and also answered privately. The second part was a social preference elicitation task providing an independent test for social preferences taken from Kerschbamer (2013; see the appendix). This was closest in design to the individual allocation task, and more distant in design, as $q$ increases from 0 , to the other treatments with median voting. Notice however that under sincere voting, if $q$ approaches 1 , the task becomes akin to an individual allocation task again. In this second part of the experiment, subjects are randomly matched with another participant in each of ten binary decisions that allocate a certain payoff to oneself and to the matched participant. One of the ten allocation decisions is paid out for real to the decision maker and the matched participant, where the payoff-relevant allocation decision is randomly determined at the end of the experiment. The ten decisions allow identifying different distributional preferences non-parametrically. Details on the procedure are provided in the appendix. 
After this, additional individual tasks followed in the third and final part of the experiment: specifically, incentivized measurements of individual risk and ambiguity preferences using a standard choice list procedure (Holt and Laury, 2002; Engle-Warnick and Laszlo, 2006; see online appendix for details), two psychological inventories (Stöber's, 2001, social desirability scale and Cacioppo et al.'s, 1984, need for cognition test), ${ }^{7}$ and a couple of questions regarding socio-demographics and individual background. ${ }^{8}$ The final stage of the experiment included feedback on the randomly selected payoff-relevant decisions in parts 1,2 and 3 of the experiment as well as on consequent individual earnings. Payments to subjects were made privately and in cash.

\section{Results}

\subsection{Overview of choices}

We start by giving an overview of the average chosen wage levels in the ten treatments. Remember that the wage can be determined by the median vote of the eligible workers or by a randomly chosen individual worker. Thus, it makes sense to distinguish between a total average (TOT) and an average including only those cases in which the median was decisive (MED) and not an according-to-probability- $q$ randomly selected group member. Only for MED, the median voter prediction based on selfish decision makers holds. For TOTpredictions based on selfish decision makers one has to take the probabilities that a single member can be decisive into account. Table 3 provides the results.

One can see that the actual figures in Table 3 are close to the predictions based on the assumption of rational and selfish decision makers (see the numbers in parentheses in the eight cells). Obviously, it is more informative to look at averages contingent on types, and we thus refrain from running non-parametric tests on the differences in Table 3. We provide averages, contingent on types, in Table 4.

\footnotetext{
${ }^{7}$ The first is a control for experimenter demand (Zizzo, 2010); the second is a control for intellectual
} curiosity.

${ }^{8}$ As we did not get interesting results using these variables (apart possibly from a small effect of higher generosity by women subjects), they are not referred to further in this paper. 
There are several ways to slice the data in Table 4 . We start by comparing wage proposals in the insider-outsider treatments (three voters) with proposals in the all-workers treatments (five voters), contingent on the type of worker. There is no significant difference between the two treatments for types 1, types 2, and types 3 (Mann-Whitney-U-tests on the individual level (average over the ten periods); $p>0.29$ in all cases; $q$-regimes are collapsed, i.e. $N=112) .{ }^{9}$ Hence, one can conclude that there does not seem to be a significant treatment effect in support of union models that take employment into account. In other words, insiders do not seem to lower their wage proposals in order to increase employment compared to the all-workers case. This is in line with our first prediction.

Obviously, a deviation from the selfish prediction in $q=0.8$ and $q=0.2$ makes only sense if one deviates to a wage level that ensures employment for at least one other worker. This is especially important for type- 2 workers in the insider-outsider treatments (potentially going from a wage of 50 to a wage of 33 or lower) and for type-3 workers in the all-workers treatments (potentially going from a wage of 33 to a wage of 25 or lower) with $q=0.8 .^{10}$

An alternative way of slicing the data is provided by comparing across the five $q$ regimes, holding the number of voters (three or five) constant, contingent on worker types. The hypothesis would be that there is a significant decline of wage proposals with $q$ 's close to 0 and, perhaps also, close to 1 , and from ex ante to ex post for types 1 to 3 . Although we will have a closer look at the influence of $q$ on wage proposals in the subsequent section, a first impression is given by two-sided Kruskal-Wallis tests. Interestingly, most tests are not significant. The only two comparisons that are (close to) significantly different across the five $q$-regimes are for types 3 in all-workers treatments $(p=0.02)$ and types 4 in all-workers treatments $(p=0.09)$. For both types, wages are highest in the intermediate $q$-range (in line with other-regarding preferences extended to uncertainty or with a relatively high $\lambda$ ).

However, it is much easier to control for several determinants of wage proposals in a parametric regression analysis, following in the next section. In the regression, we shall also control for the development over the ten periods. Furthermore, the regression allows

\footnotetext{
${ }^{9}$ All $p$-values reported in this paper are based on two-sided hypothesis tests.

${ }^{10}$ An online appendix shows the distribution of wage proposals, split up according to treatments and
} types. 
controlling for individual measures of other-regarding preferences and uncertainty preferences.

\subsection{Econometric analysis}

We continue with a regression analysis of our data. Table 5 contains a multiple level random effects censored regression model on the wage proposal. It simultaneously controls for the non-independence of observations at the level of subjects (since each subject makes ten choices) and at the level of the group (since a common history is established in each group after the first period), as well as for the wage proposal being between 0 and 100. Type 1, Type 2, Type 3 and Type 4 are dummy variables for workers of the respective type (e.g., Type $1=1$ with a type-1 worker, else 0 ). Median chance is our $q$-varying accountability effect variable. It is equal to 1 with the treatments with a $100 \%$ chance that the voting outcome becomes implemented, 0.8 with the treatments with a $80 \%$ chance that the voting outcome becomes implemented, 0.2 with the treatments with a $20 \%$ chance that the voting outcome becomes implemented and 0 when there is no voting outcome. Ex ante is a dummy variable set equal to 0 with the treatments where one worker is always chosen ex post as a dictatorial wage setter and equal to 1 with the treatments where one worker is chosen ex ante to be the dictatorial wage setter. INS is the treatment dummy for whether everyone is an insider to the trade union $(=1)$ or whether only three workers are $(=0)$. Incentivized enables us to control for whether a decision is incentivized, as most are, or not; specifically, it is a dummy equal to 1 if a decision is incentivized. Period captures the period, between 1 and 10, and hence within-experiment experience. Prior experience (= 1 for subjects with experience in previous, albeit unrelated, experiments) is a dummy capturing between-experiments as opposed to within-experiment experience. Inequality averse and altruistic are dummies for whether a subject has been respectively classified as inequality averse or altruistic using our independent social preference elicitation task (see the appendix), a standard incentivized measurement of social preferences following Kerschbamer (2013).

Finally, we include some interaction variables involving the type dummies with (a) Median chance, to enable us to verify the sensitivity of type dummies effects to changes in $q$ and with Ex ante to identify how close the decision environment is to that of a unionized labor market, or (b) Inequality averse, as behavior of subjects classified as inequality averse by the 
preference elicitation task may change depending on where they stand in terms of social preferences, or (c) Altruistic, for similar reasons in relation to subjects classified as altruists.

One of the results from the descriptive analysis of Section 3.1 is that, in line with the first empirical prediction of our model, full or partial union membership do not affect wage proposals for the worker types that make proposals in both cases (types 1,2 and 3); this remains the case in the regression analysis $(p=0.183)$. Another result from the descriptive analysis is that wage proposals are sensitive to the worker type. Table 5 corroborates this finding, with the highest wage proposals observed for type-1 workers $(p<0.001)$, followed at a distance by type $2(p<0.001)$, followed by type $3(p<0.001)$, followed by type $4(\mathrm{p}<0.05)$ and type-5 workers. These observations are in line with the second empirical prediction of our model, even though of course they are not surprising.

Table 5 shows a significant effect for Type $1 \times$ Ex ante $(p=0.002) .{ }^{11}$ Put differently, type-1 workers make lower wage proposals, i.e. behave more kindly, only when they know ex ante that their wage proposal will be the one that gets implemented. This is consistent with an accountability effect as discussed in the introduction and, thus, inconsistent with the fourth prediction of our model that do not incorporate accountability directly.

Result 1. Having a full rather than partial trade union membership has no effect on the wage proposals. This is in line with our first prediction.

Result 2. Wage proposals are differentiated by worker type and in the direction predicted by our model. This fits our second prediction.

Result 3. Type-1 workers behave less kindly when they do not know whether they will affect the actual wage. This is consistent with an accountability effect and thus inconsistent with the fourth prediction of our model.

The coefficients on Inequality averse and Altruistic need to be interpreted in combination with those on the interaction terms. The net effect of inequality aversion on type-

\footnotetext{
${ }^{11}$ Note that, while the coefficient on Ex Ante is positive (if statistically insignificant), the one on Type $1 x$ Ex Ante more than offsets it by over 2 to 1 .
} 
1 workers is to make them propose lower wages, though the marginal effect is way lower than the large push up in high wage proposals due to the strategic incentive to do so. Put it differently, inequality averse type-1 workers still make higher wage proposals by approximately 59 points. ${ }^{12}$ There is no net effect of inequality aversion in the direction of the third prediction for the other types. The net effect of altruism on type-1 workers is considerably smaller than that of inequality aversion; altruistic type 1 workers make higher wage proposals by approximately 71 points.

Result 4. Being classified as inequality averse or altruistic in the preference elicitation task predicts comparatively kind behavior for type-1 workers (only), which is consistent with the third prediction of our model for this type (only). Being classified as inequality averse leads to comparatively kinder behavior by type-1 workers than being classified as altruist.

Unsurprisingly, incentivized choices lead to higher (that is, less kind) wage proposals ( $p$ $<0.001$ in Table 5).

\section{Discussion and conclusion}

We implemented a very stylized wage setting based on union members voting on their preferred wages and, consequently, implementing a certain employment level. Workers are heterogeneous in terms of their productivity, and there is thus a conflict among selfish workers with regard to the optimal wage. In line with our theoretical prediction, there is no difference in wage proposals between a setting in which all five workers vote on the wage level and a setting in which only the three most productive workers are allowed to vote. The more the voting system is transformed from a median voter scheme to an individual allocation task, the more employment levels should be taken into account by workers if there is a feeling of accountability or responsibility of workers. However, such an effect is only observed with ex ante dictatorship for type-1 players. Overall, the level of pro-social preferences we found is

\footnotetext{
${ }^{12}$ This is found combining the coefficients on Type 1, Inequality averse and Type $1 \mathrm{x}$ Inequality averse.
} 
small; however, independent measures of pro-social preferences are still a good predictor for wage proposals of at least some (that is, the type-1) workers. While the average wage levels under $q=1$ indicate a slight shift towards more other-regarding behavior compared to $q=0.8$ and $q=0.2$, such an effect is not systematically present in the regression results, and we do not want to over-interpret any findings along those lines. ${ }^{13}$

Our setup incorporates an allocation decision into a labor market setting and disentangles the effects from the individual allocation task and the median voter decision by union members. Both the union frame and the gradual transformation from a median voter scheme to a dictator scheme are unique in the behavioral economics literature. They allow for several potential extensions beyond this paper. Naturally, one has to exercise caution when generalizing the results from the experiment to real wage setting environments. It was not the aim of this experiment to capture the peculiarities of natural institutions and the behavior of unions. For instance, there is variation of responsibility of union leadership and such variation parallels, at least to a certain extent, our treatment variation. However, we cannot capture any kind of strategic bargaining aspects that underlie the relationship between ordinary union members and union leadership. Hence, we want to be very cautious in our claims. Nonetheless, there are a couple of findings from the experiment that provide implications for the real world. First, voting systems in allocation tasks seem to have the tendency to reduce accountability and, thus, lead to more selfish outcomes than systems in which single decision makers, though still anonymous, can be held accountable. Second, the size of the union does not seem to play a large role in the allocative function through wage setting beyond the mechanic effect of the median voter scheme. Of course, it is possible that the size of the union is important in another dimension, namely in determining the power of a union, which we neglected here.

We complement results from the empirical literature based on data from the field. The literature has, for instance, looked at wage compression effects of union membership (Card et al., 2004; Dustmann and Schönberg, 2009). The advantages of experiments are causal inference on the treatment variables and the possibility of pinning down the exact mechanisms for any effects. Extending our setup is, thus, important to establish generalizability. Several

${ }^{13}$ Adding a $q=1$-related set of dummy variables in the regressions does not change our conclusion. Hence, the exact specification does not seem to be an explanation. 
dimensions seem worthwhile investigating. One could think of varying the parameters of our setup, especially the distribution and the exact choice of productivity levels of workers. One could also introduce uncertainties over certain aspects of the interaction. Further, it seems interesting to analyze different forms of interaction among union members beyond the stylized voting game used in the current experiment, which would make membership potentially more salient. Obviously, changing union size could be an aspect worthwhile exploring.

\section{Funding}

This work was supported by CBESS at the University of East Anglia and by the University of Munich.

\section{Acknowledgements}

We thank the editors, two anonymous reviewers, Marvin Deversi, Nadja Furtner, Jana Jarecki, Jia Liu, and Julius Pahlke for excellent research assistance, and Anders Poulsen for very helpful comments. The usual disclaimer applies. 


\section{References}

Abbink K, Herrmann B. The Moral Costs of Nastiness. Economic Inquiry 2011: 49; 631-633

Balafoutas L, Kerschbamer R, Kocher MG, Sutter, M. Revealed Distributional Preferences: Individuals vs. Teams. Journal of Economic Behavior and Organization, forthcoming

Bardsley N. Dictator Game Giving: Altruism or Artefact? Experimental Economics 2008: 1; $122-133$

Blair DH, Crawford DL. Labor Union Objectives and Collective Bargaining. Quarterly Journal of Economics 1984: 99; 547-566

Bohnet I, Frey B. The Sound of Silence in Prisoner's Dilemma and Dictator Games. Journal of Economic Behavior and Organization 1999: 38; 43-57

Bolton GE, Ockenfels A. ERC: A Theory of Equity, Reciprocity, and Competition. American Economic Review 2000: 90; 166-193

Bornstein G, Yaniv I. Individual and Group Behavior in the Ultimatum Game: Are Groups More "Rational" Players? Experimental Economics 1998: 1; 101-108

Cacioppo JT, Petty R, Feng Kao C. The Efficient Assessment of Need for Cognition. Journal of Personality Assessment 1984: 48; 306-307

Card D, Lemieux T, Riddell WC. Unions and Wage Inequality Journal of Labor Research 2004: $25 ; 519-559$

Charness G, Rigotti L, Rustichini A. Individual Behavior and Group Membership. American Economic Review 2007: 97; 1340-1352

Charness G, Rabin M. Understanding Social Preferences with Simple Tests. Quarterly Journal of Economics 2002: 117; 817-869

Charness G, Sutter M. Groups Make Better Self-interested Decisions. Journal of Economic Perspectives 2012: 26, 157-176

Chen Y, Li S. Group Identity and Social Preferences. American Economic Review 2009: 99; $431-457$ 
Dana J, Weber R, Kuang J X. Exploiting Moral Wriggle Room: Behavior Inconsistent with a Preference for Fair Outcomes. Economic Theory 2007: 33; 67-80

Dufwenberg M, Kirchsteiger G. A Theory of Sequential Reciprocity. Games and Economic Behavior 2004: 47; 268-298

Dustmann C, Schönberg U. Training and Union Wages. Review of Economics and Statistics 2009: $91 ; 363-376$

Eckel C, Grossman P. Altruism in Anonymous Dictator Games. Games and Economic Behavior 1996: 16; 181-191

Ellingsen T, Johannesson M. Pride and Prejudice: The Human Side of Incentive Theory. American Economic Review 2008: 98; 990-1008

Engelmann D, Strobel M. Inequality Aversion, Efficiency, and Maximin Preferences in Simple Distribution Experiments. American Economic Review 2004: 94; 857-869

Engle-Warnick J, Laszlo S. Learning-by-Doing in an Ambiguous Environment. McGill University Department of Economics Working Paper, 2006s-29; 2006

Falk A, Fischbacher U. A Theory of Reciprocity. Games and Economic Behavior 2006: 54; 293-315

Farber H. Individual Preferences and Union Wage Determination: the Case of United Mine Workers. Journal of Political Economy 1978: 86; 932-942

Fehr E, Schmidt KM. A Theory of Fairness, Competition, and Cooperation. Quarterly Journal of Economics 1999: 114; 817-868

Fischbacher U. z-Tree: Zurich Toolbox for Ready-Made Economic Experiments. Experimental Economics 2007: 10; 171-178

Forsythe R, Horowitz JL, Savin, N E, Sefton, M. Fairness in Simple Bargaining Games. Games and Economic Behavior 1994: 6; 347-369

Greiner B. Subject Pool Recruitment Procedures: Organizing Experiments with ORSEE. Journal of the Economic Science Association 2015: 1; 114-125.

Grossman, G. Union Wages, Seniority and Employment. American Economic Review 1983: $73 ; 277-290$ 
Güth, W, Huck, S, Ockenfels, P. Two-Level Ultimatum Bargaining with Incomplete Information: an Experimental Study. Economic Journal 1996: 106; 593-604

Hargreaves Heap SP, Zizzo DJ. The Value of Groups. American Economic Review 2009: 99; 295-323

Hoffman E, McCabe K, Shachat K, Smith V. Social Distance and Other-Regarding Behavior in Dictator Games. American Economic Review 1996: 86; 653-660

Holt CA, Laury SK. Risk Aversion and Incentive Effects. American Economic Review 2002: 92; 1644-1655

Insko C, Hoyle R, Pinkley R, Hong G, Slim R, Dalton G, Lin Y, Ruffin W, Dardis G, Bernthal P, Schopler J. Individual-Group Discontinuity: The Role of a Consensus Rule. Journal of Experimental Social Psychology 1988: 24; 505-519

Insko, C, Pinkley R, Hoyle R, Dalton B, Hong G, Slim R, Landry P, Holton B, Ruffin P, Thibaut J. Individual versus Group Discontinuity: The Role of Intergroup Contact. Journal of Experimental Social Psychology 1987: 23; 250-267

List JA. On the Interpretation of Giving in Dictator Games. Journal of Political Economy 2007: $115 ; 482-493$

Kahneman D, Knetsch JL, Thaler R. Fairness and the Assumptions of Economics. Journal of Business 1986: 59; 285-300

Kerschbamer R. The Geometry of Distributional Preferences and a Non-Parametric Identification Approach. European Economic Review 2015: 76; 85-103.

Kocher MG, and Sutter M. Individual versus Group Behavior and the Role of the Decision Making Procedure in Gift-Exchange Experiments. Empirica 2007: 34; 63-88

Kugler T, Bornstein G, Kocher MG, Sutter M. Trust between Individuals and Groups: Groups are Less Trusting than Individuals but Just as Trustworthy. Journal of Economic Psychology 2007: 28; 646-657

Kugler T, Kausel E, Kocher MG. Are Groups More Rational Than Individuals? A Review of Interactive Decision Making in Groups. WIREs Cognitive Science 2012: 3; 471-482 
Linbeck A, Snower D. The Insider-Outsider Theory of Employment and Unemployment, MIT Press, Cambridge, Massachusetts; 1988

Luhan, WJ, Kocher MG, Sutter, M. Group Polarization in the Team Dictator Game Reconsidered. Experimental Economics 2009: 12; 26-41

MacDonald I, Solow R. Wage Bargaining and Employment. American Economic Review 1981: 71; 896-908

Pahlke J, Strasser S, Vieider F. Risk-Taking for Others under Accountability. Economics Letters 2012: 114; 102-105

Rabin M. Incorporating Fairness into Game Theory and Economics. American Economic Review 1993: 83; 1281-1302

Starmer C, Sugden, R. Does the Random-Lottery Incentive System Elicit True Preferences? An Experimental Investigation. American Economic Review 1991: 81; 971-978

Stöber J, The Social Desirability Scale-17 (SDS-17). European Journal of Psychological Assessment 2001: 17; 222-232

Sutter M. Individual Behavior and Group Membership: Comment. American Economic Review 2009: 99; 2247-2257

Tajfel H, Billig, MG, Bundy RP, Flament C. Social Categorization and Intergroup Behavior. European Journal of Social Psychology 1971: 1; 149-178

Vieider F. Moderate Stake Variations for Risk and Uncertainty, Gains and Losses: Methodological Implications for Comparative Studies. Economics Letters 2012: 117; $718-721$

Zizzo DJ. Experimenter Demand Effects in Economic Experiments. Experimental Economics 2010: $13 ; 75-98$ 


\section{Figures}

Figure 1: Graphical treatments overview

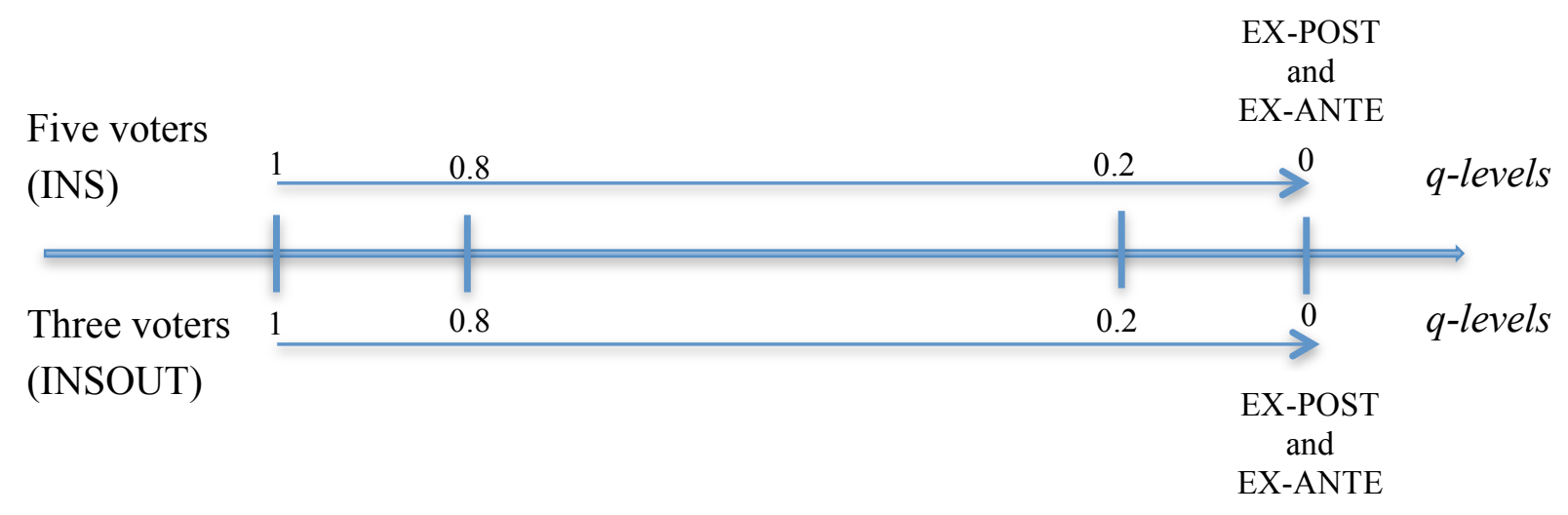




\section{Tables}

Table 1: Wages and employment

\begin{tabular}{|c|c|}
\hline Wage level (in experimental points) & These worker types are employed \\
\hline $1-20$ & $1,2,3,4,5$ \\
\hline $21-25$ & $1,2,3,4$ \\
\hline $26-33$ & $1,2,3$ \\
\hline $34-50$ & 1,2 \\
\hline $51-100$ & 1 \\
\hline
\end{tabular}

Table 2: Treatment overview

\begin{tabular}{|c|c|c|c|c|c|}
\hline & $\boldsymbol{q}=\mathbf{1}$ & $\boldsymbol{q}=\mathbf{0 . 8}$ & $\boldsymbol{q}=\mathbf{0 . 2}$ & $\boldsymbol{q}=\mathbf{0}$ (EX-POST) & $\boldsymbol{q}=\mathbf{0}$ (EX-ANTE) \\
\hline Five voters & INS-1 & INS-0.8 & INS-0.2 & INS-0 & INS-0 \\
& $n=40$ & $n=60$ & $n=60$ & (EX-POST) & (EX-ANTE) \\
& & & & $n=60$ & $n=60$ \\
\hline Three voters & INSOUT-1 & INSOUT-0.8 & INSOUT-0.2 & INSOUT-0 & INSOUT-0 \\
& $n=40$ & $n=60$ & $n=60$ & (EX-POST) & (EX-ANTE) \\
& & & & $n=40$ & $n=40$ \\
\hline
\end{tabular}

Note: $n$ denotes the number of participants in the respective treatment

Table 3: Average chosen wage levels (selfish prediction in parentheses)

\begin{tabular}{|c|c|c|c|c|c|}
\hline & $\boldsymbol{q}=\mathbf{1}$ & $\boldsymbol{q}=\mathbf{0 . 8}$ & $\boldsymbol{q}=\mathbf{0 . 2}$ & $\begin{array}{c}\boldsymbol{q}=\mathbf{0} \\
\text { (EX-POST })\end{array}$ & $\begin{array}{c}\boldsymbol{q}=\mathbf{0} \\
\text { (EX-ANTE) }\end{array}$ \\
\hline Five & MED: 41.26 & MED: 30.73 & MED: 34.52 & MED: not appl. & MED: not appl. \\
voters & TOT: 41.26 & TOT: 33.43 & TOT: 45.43 & TOT: 41.62 & TOT: 45.58 \\
& $(w=33$ for MED $)$ & $(w=33$ for MED $)$ & $(w=33$ for MED $)$ & $(w=45.6$ for TOT $)$ & $(w=45.6$ for TOT $)$ \\
\hline Three & MED: 30.92 & MED: 45.87 & MED: 46.00 & MED: not appl. & MED: not appl. \\
voters & TOT: 30.92 & TOT: 50.82 & TOT: 64.68 & TOT: 56.26 & TOT: 60.64 \\
& $(w=50$ for MED $)$ & $(w=50$ for MED $)$ & $(w=50$ for MED $)$ & $(w=61$ for TOT $)$ & $(w=61$ for TOT $)$ \\
\hline
\end{tabular}

MED refers to periods in which the median was decisive; TOT refers to the total average, including all periods. $\mathbf{q}=\mathbf{0}$ (EX-ANTE) only includes incentivized choices. 
Table 4: Average wage proposal by relevant types (selfish predictions in parentheses)

\begin{tabular}{|c|c|c|c|c|c|}
\hline & $\boldsymbol{q}=\mathbf{1}$ & $\boldsymbol{q}=\mathbf{0 . 8}$ & $\boldsymbol{q}=\mathbf{0 . 2}$ & $\boldsymbol{q}=\mathbf{0}(\mathbf{E X}-\mathrm{POST})$ & $\boldsymbol{q}=\mathbf{0}($ EX-ANTE) \\
\hline \multirow{2}{*}{ Five voters } & $\mathrm{T} 1: 77.48(100)$ & $\mathrm{T} 1: 88.71(100)$ & $\mathrm{T} 1: 79.79(100)$ & $\mathrm{T} 1: 79.04(100)$ & $\mathrm{T} 1: 80.79(100)$ \\
& $\mathrm{T} 2: 49(50)$ & $\mathrm{T} 2: 50.25(50)$ & $\mathrm{T} 2: 43.84(50)$ & $\mathrm{T} 2: 47.83(50)$ & $\mathrm{T} 2: 44.40(50)$ \\
& $\mathrm{T} 3: 27.32(33)$ & $\mathrm{T} 3: 34.03(33)$ & $\mathrm{T} 3: 38.05(33)$ & $\mathrm{T} 3: 31.68(33)$ & $\mathrm{T} 3: 31.72(33)$ \\
& $\mathrm{T} 4: 21.03(25)$ & $\mathrm{T} 4: 20.13(25)$ & $\mathrm{T} 4: 28.04(25)$ & $\mathrm{T} 4: 24.91(25)$ & $\mathrm{T} 4: 24.32(25)$ \\
& $\mathrm{T} 5: 31.48(20)$ & $\mathrm{T} 5: 19.23(20)$ & $\mathrm{T} 5: 24.68(20)$ & $\mathrm{T} 5: 18.90(20)$ & $\mathrm{T} 5: 20.25(20)$ \\
\hline \multirow{2}{*}{ Three voters } & $\mathrm{T} 1: 83.35(100)$ & $\mathrm{T} 1: 87.10(100)$ & $\mathrm{T} 1: 89.64(100)$ & $\mathrm{T} 1: 72.16(100)$ & $\mathrm{T} 1: 80.29(100)$ \\
& $\mathrm{T} 2: 39.93(50)$ & $\mathrm{T} 2: 46.00(50)$ & $\mathrm{T} 2: 46.45(50)$ & $\mathrm{T} 2: 46.35(50)$ & $\mathrm{T} 2: 42.86(50)$ \\
& $\mathrm{T} 3: 31.68(33)$ & $\mathrm{T} 3: 32.31(33)$ & $\mathrm{T} 3: 30.42(33)$ & $\mathrm{T} 3: 30.59(33)$ & $\mathrm{T} 3: 28.26(33)$ \\
\hline
\end{tabular}


Table 5: Multi level Tobit regression on wage proposals

\begin{tabular}{|c|c|c|}
\hline & $\beta$ & $\mathrm{Se}$ \\
\hline Type 1 & $75.710 * * *$ & $(4.542)$ \\
\hline Type 2 & $33.437 * * *$ & $(4.188)$ \\
\hline Type 3 & $18.832 * * *$ & $(4.259)$ \\
\hline Type 4 & $9.335^{*}$ & (4.563) \\
\hline Median Chance & 0.008 & $(0.044)$ \\
\hline Ex Ante & 7.606 & $(5.138)$ \\
\hline INS & 2.157 & $(1.621)$ \\
\hline Prior experience & $12.466^{* * *}$ & (2.748) \\
\hline Incentivized & $5.369 * * *$ & $(1.125)$ \\
\hline Inequality averse & $12.108 * *$ & $(4.371)$ \\
\hline Altruistic & $11.026^{* *}$ & $(3.748)$ \\
\hline Type 1 x median chance & 0.004 & $(0.058)$ \\
\hline Type $2 \times$ median chance & $-0.121 *$ & $(0.052)$ \\
\hline Type $3 \times$ median chance & -0.030 & $(0.053)$ \\
\hline Type $4 \times$ median chance & -0.036 & $(0.055)$ \\
\hline Type $1 \mathrm{x}$ ex ante & $-19.479 * *$ & $(6.236)$ \\
\hline Type $2 \mathrm{x}$ ex ante & -7.630 & $(6.137)$ \\
\hline Type $3 \mathrm{x}$ ex ante & -4.978 & $(6.153)$ \\
\hline Type $4 \mathrm{x}$ ex ante & -2.718 & $(6.818)$ \\
\hline Type $1 \mathrm{x}$ inequality averse & $-29.190 * * *$ & $(5.454)$ \\
\hline Type $2 \mathrm{x}$ inequality averse & $-12.171^{*}$ & $(5.160)$ \\
\hline Type $3 \mathrm{x}$ inequality averse & $-13.528 *$ & $(5.235)$ \\
\hline Type $4 \mathrm{x}$ inequality averse & -9.681 & $(5.438)$ \\
\hline Type $1 \mathrm{x}$ altruistic & $-15.899 * *$ & $(5.338)$ \\
\hline Type $2 \mathrm{x}$ altruistic & $-13.541 * *$ & $(4.737)$ \\
\hline Type $3 \mathrm{x}$ altruistic & $-14.160 * *$ & $(4.905)$ \\
\hline Type $4 \mathrm{x}$ altruistic & -8.550 & $(5.079)$ \\
\hline Period & $0.138^{*}$ & $(0.066)$ \\
\hline Constant & -4.068 & $(4.731)$ \\
\hline
\end{tabular}

Notes: $n=4300$. The nested random effect regression simultaneously controls for both group level and subject level non-independence of observations, and for the censoring of the dependent variable (min value: 0 ; max value: 100 ). The regression was estimated using Stata/MP 14.0, with numbers rounded to 3 decimal places. ${ }^{*} p<0.05, * * p<0.01, * * * p<0.001$. 


\section{Appendix A: Proofs of Propositions 1 and 2}

\section{Proof of Proposition 1:}

Suppose $0 \leq \lambda<1$. To prove that the strategy profile $\left(\mathrm{w}_{1}, \mathrm{w}_{2}, \mathrm{w}_{3}\right)=\left(\mathrm{Q}_{1}, \mathrm{Q}_{2}, \mathrm{Q}_{3}\right)$ is a unique Nash equilibrium, we show that setting $\mathrm{w}_{\mathrm{i}}=\mathrm{Q}_{\mathrm{i}}$ is a strictly dominant strategy for worker $\mathrm{i}$.

Suppose first worker 1 is decisive (i.e., worker 1's wage has been randomly chosen). Then $\mathrm{w}_{1}=\mathrm{Q}_{1}$ is optimal if $100>\max \left\{50(2)^{\lambda},(100 / 3)(3)^{\lambda}, 25(4)^{\lambda}, 20(5)^{\lambda}\right\}$. This holds when $\lambda<1$. Similarly, when worker 2 is decisive, $\mathrm{w}_{2}=\mathrm{Q}_{2}$ is optimal when $50(2)^{\lambda}>\max \left\{(100 / 3)(3)^{\lambda}, 25(4)^{\lambda}, 20(5)^{\lambda}\right\}$. This again holds when $\lambda<1$. Finally, when worker 3 is decisive, $\mathrm{w}_{3}=\mathrm{Q}_{3}$ is optimal when $(100 / 3)(3)^{\lambda}>\max \left\{25(4)^{\lambda}, 20(5)^{\lambda}\right\}$. Once more, this is satisfied when $\lambda<1$.

We next show that under the median rule worker $i$ receives a payoff from $\mathrm{w}_{\mathrm{i}}=\mathrm{Q}_{\mathrm{i}}$ that is at least as high as, or strictly higher than, the payoff from any other choice of $\mathrm{w}_{\mathrm{i}}$, in any strategy profile. This follows from the fact that, whatever the other workers' choices, worker i moves the median wage closest to her optimal value, which, when $0 \leq \lambda<1$, is $Q_{i}$, by setting $\mathrm{w}_{\mathrm{i}}=\mathrm{Q}_{\mathrm{i}}$ (other values of $\mathrm{w}_{\mathrm{i}}$ may be equally optimal, but $\mathrm{w}_{\mathrm{i}}=\mathrm{Q}_{\mathrm{i}}$ is always among the set of optimal choices). To be more precise, suppose the two other workers set their wages below or equal to $\mathrm{Q}_{\mathrm{i}}$. Then any wage $\mathrm{w}_{\mathrm{i}}$ equal to or above the largest of these wages is optimal. Second, suppose one of the other workers sets his wage below $\mathrm{Q}_{i}$ and the other worker sets his wage above or equal to $\mathrm{Q} i$. Then a unique best reply is $\mathrm{w}_{\mathrm{i}}=\mathrm{Q}_{\mathrm{i}}$. Finally, suppose each of the two other workers set their wage equal to or above Qi. Then any wage $\mathrm{w}_{\mathrm{i}}$ is optimal. It follows that under the median rule $\mathrm{w}_{\mathrm{i}}=\mathrm{Q}_{\mathrm{i}}$ is a best reply, regardless of the wage choices of the two other workers. Combining this with the analysis for when the worker is decisive shows that setting $\mathrm{w}_{\mathrm{i}}=\mathrm{Q}_{\mathrm{i}}$ is a strictly dominant strategy, and hence the profile $\left(\mathrm{w}_{1}, \mathrm{w}_{2}, \mathrm{w}_{3}\right)=\left(\mathrm{Q}_{1}, \mathrm{Q}_{2}, \mathrm{Q}_{3}\right)$ is the unique Nash equilibrium.

Suppose now $\lambda=1$. When worker $\mathrm{i}$ is decisive, each of the wages $\left\{\mathrm{Q}_{\mathrm{i}}, \ldots, \mathrm{Q}_{5}\right\}$ is a best reply. This implies that any profile $\left(\mathrm{w}_{1}, \mathrm{w}_{2}, \mathrm{w}_{3}\right)$ such that $\mathrm{w}_{\mathrm{i}} \in\left\{\mathrm{Q}_{\mathrm{i}}, \ldots, \mathrm{Q}_{5}\right\}$ is a Nash equilibrium, because when worker $\mathrm{i}$ is decisive any wage $\mathrm{w}_{\mathrm{i}} \in\left\{\mathrm{Q}_{\mathrm{i}}, \ldots, \mathrm{Q}_{5}\right\}$ is optimal. Under the median rule, any wage $\mathrm{w}_{\mathrm{i}} \in\left\{\mathrm{Q}_{\mathrm{i}}, \ldots, \mathrm{Q}_{5}\right\}$ is once more optimal. To see this, suppose first that each of the two workers has chosen a wage below or equal to $\mathrm{Q}_{\mathrm{i}}$. In this case any wage $\mathrm{w}_{\mathrm{i}} \in\left\{\mathrm{Q}_{1}, \ldots, \mathrm{Q}_{5}\right\}$ is 
optimal for worker i. Suppose then one worker has chosen a wage below Qi, and the other has chosen a wage above or equal to Qi. Then any wage $\mathrm{w}_{\mathrm{i}} \in\left\{\mathrm{Q}_{\mathrm{i}}, \ldots, \mathrm{Q}_{5}\right\}$ is optimal. Finally, suppose both other workers choose a wage equal to or above $\mathrm{Q}_{\mathrm{i}}$. Then, any wage $\mathrm{w}_{\mathrm{i}} \in\left\{\mathrm{Q}_{1}, \ldots, \mathrm{Q}_{5}\right\}$ is optimal for worker $\mathrm{i}$. This implies that no matter what the other workers decide, any wage $\mathrm{w}_{\mathrm{i}} \in\left\{\mathrm{Q}_{\mathrm{i}}, \ldots, \mathrm{Q}_{5}\right\}$ is optimal under the median rule. Any profile $\left(\mathrm{w}_{1}, \mathrm{w}_{2}, \mathrm{w}_{3}\right)$ such that $\mathrm{w}_{\mathrm{i}} \in\left\{\mathrm{Q}_{\mathrm{i}}, \ldots, \mathrm{Q}_{5}\right\}$ is therefore a Nash equilibrium.

Suppose now that $\lambda>1$. We show that setting $\mathrm{w}_{\mathrm{i}}=\mathrm{Q}_{5}$ is a strictly dominant strategy for each worker. When decisive, $\mathrm{w}_{1}=\mathrm{Q}_{5}$ is optimal for worker 1 when $20(5)^{\lambda}>\max \left\{100,50(2)^{\lambda},(100 / 3)(3)^{\lambda}, 25(4)^{\lambda}\right\}$. This holds when $\lambda>1$. When worker 2 is decisive, $\mathrm{w}_{2}=\mathrm{Q}_{5}$ is optimal if $20(5)^{\lambda}>\max \left\{50(2)^{\lambda},(100 / 3)(3)^{\lambda}, 25(4)^{\lambda}\right\}$, and this again holds when $\lambda>1$. Finally, consider worker 3 . When he is decisive, $w_{3}=Q_{5}$ is optimal when $20(5)^{\lambda}>\max \left\{(100 / 3)(3)^{\lambda}, 25(4)^{\lambda}\right\}$, and this again holds when $\lambda>1$.

Under the median rule, when $\lambda>1$, worker i's best outcome is that the median wage is $\mathrm{Q}_{5}$. Thus, irrespective of the other workers' wage choices, worker i will want to bring the median as close to $\mathrm{Q}_{5}$ as possible; setting $\mathrm{w}_{\mathrm{i}}=\mathrm{Q}_{5}$ is always the, potentially non-unique, wage that accomplishes this objective. This shows that setting $\mathrm{w}_{\mathrm{i}}=\mathrm{Q}_{5}$ is a strictly dominant strategy for each worker $\mathrm{i}$ when $\lambda>1$. This, in turn implies that the Nash equilibrium $\left(\mathrm{w}_{1}, \mathrm{w}_{2}, \mathrm{w}_{3}\right)=\left(\mathrm{Q}_{5}, \mathrm{Q}_{5}\right.$, $\mathrm{Q}_{5}$ ) is unique when $\lambda>1$.

\section{Proof of Proposition 2:}

Suppose $\lambda<1$. The proof that the strategy profile $\left(\mathrm{w}_{1}, \mathrm{w}_{2}, \mathrm{w}_{3}, \mathrm{~W}_{4}, \mathrm{~W}_{5}\right)=\left(\mathrm{Q}_{1}, \mathrm{Q}_{2}, \mathrm{Q}_{3}, \mathrm{Q}_{4}, \mathrm{Q}_{5}\right)$ is a unique Nash equilibrium is a straightforward generalization of the proof of Proposition 1.

Similarly, when $\lambda=1$, the proof that there are multiple equilibria again follows from a generalization of the proof for the corresponding part of Proposition 1. Finally, suppose $\lambda>1$. The proof that $\left(\mathrm{w}_{1}, \mathrm{w}_{2}, \mathrm{w}_{3}, \mathrm{w}_{4}, \mathrm{w}_{5}\right)=\left(\mathrm{Q}_{5}, \mathrm{Q}_{5}, \mathrm{Q}_{5}, \mathrm{Q}_{5}, \mathrm{Q}_{5}\right)$ is the unique equilibrium is once more a straightforward generalization of the three-worker analysis from Proposition 1. 
Appendix B: Social preference elicitation task (based on Kerschbamer, 2015)

Disadvantageous Inequality Block

\begin{tabular}{|c|c|c|c|c|}
\hline \multicolumn{2}{|c|}{ LEFT } & $\begin{array}{c}\text { Your Choice } \\
\text { (please mark) }\end{array}$ & \multicolumn{2}{|c|}{ RIGHT } \\
\hline $\begin{array}{l}\text { you } \\
\text { get }\end{array}$ & $\begin{array}{c}\text { passive } \\
\text { agent gets }\end{array}$ & & $\begin{array}{l}\text { you } \\
\text { get }\end{array}$ & $\begin{array}{c}\text { passive agent } \\
\text { gets }\end{array}$ \\
\hline 15 Points & 30 Points & LEFT $\bigcirc \bigcirc$ RIGHT & 20 Points & 20 Points \\
\hline 19 Points & 30 Points & LEFT $\bigcirc \bigcirc$ RIGHT & 20 Points & 20 Points \\
\hline 20 Points & 30 Points & LEFT $\bigcirc \bigcirc$ RIGHT & 20 Points & 20 Points \\
\hline 21 Points & 30 Points & LEFT $\bigcirc \bigcirc$ RIGHT & 20 Points & 20 Points \\
\hline 25 Points & 30 Points & LEFT $\bigcirc \bigcirc$ RIGHT & 20 Points & 20 Points \\
\hline
\end{tabular}

Advantageous Inequality Block

\begin{tabular}{|c|c|c|c|c|}
\hline \multicolumn{2}{|c|}{ LEFT } & \multirow{2}{*}{$\begin{array}{l}\text { Your Choice } \\
\text { (please mark) }\end{array}$} & \multicolumn{2}{|c|}{ RIGHT } \\
\hline $\begin{array}{l}\text { you } \\
\text { get }\end{array}$ & $\begin{array}{c}\text { passive } \\
\text { agent gets }\end{array}$ & & $\begin{array}{c}\text { You } \\
\text { get }\end{array}$ & $\begin{array}{c}\text { passive agent } \\
\text { gets }\end{array}$ \\
\hline 15 Points & 10 Points & LEFT $\bigcirc \bigcirc$ RIGHT & 20 Points & 20 Points \\
\hline 19 Points & 10 Points & LEFT $\bigcirc \bigcirc$ RIGHT & 20 Points & 20 Points \\
\hline 20 Points & 10 Points & LEFT $\bigcirc \bigcirc$ RIGHT & 20 Points & 20 Points \\
\hline 21 Points & 10 Points & LEFT $\bigcirc \bigcirc$ RIGHT & 20 Points & 20 Points \\
\hline 25 Points & 10 Points & LEFT $\bigcirc \bigcirc$ RIGHT & 20 Points & 20 Points \\
\hline
\end{tabular}




\section{Translation of Choices in the Distributional-Preferences Elicitation Task into WTP}

\section{Disadvantageous Inequality Block (DIP)}

\begin{tabular}{|c|c|c|c|c|}
\hline $\begin{array}{l}\text { in the DIB subject } \\
\text { chooses LEFT for the }\end{array}$ & \multicolumn{3}{|c|}{$W T P^{d}$} & $\begin{array}{c}\text { proxy for } W T P^{d} \\
\text { used }\end{array}$ \\
\hline 1 & +0.5 & $\leq W T P^{d}$ & & +0.5 \\
\hline 2 & +0.1 & $\leq W T P^{d}<$ & +0.5 & +0.3 \\
\hline 3 & +0.0 & $\leq W T P^{d}<$ & +0.1 & +0.05 \\
\hline 4 & -0.1 & $\leq W T P^{d}<$ & -0.0 & -0.05 \\
\hline 5 & -0.5 & $\leq W T P^{d}<$ & -0.1 & -0.3 \\
\hline never & & $W T P^{d}$ & -0.5 & -0.5 \\
\hline
\end{tabular}

\section{Advantageous Inequality Block (AIB)}

\begin{tabular}{|c|c|c|c|c|}
\hline $\begin{array}{c}\text { in the AIB subject } \\
\text { chooses LEFT for the } \\
\text { first time in row }\end{array}$ & \multicolumn{3}{|c|}{$W T P^{a}$} & $\begin{array}{c}\text { proxy for } W T P^{a} \\
\text { used }\end{array}$ \\
\hline 1 & & $W T P^{a} \leq$ & -0.5 & $\mathbf{- 0 . 5}$ \\
\hline 2 & -0.5 & $<W T P^{a} \leq$ & -0.1 & $\mathbf{- 0 . 3}$ \\
\hline 3 & -0.1 & $<W T P^{a} \leq$ & -0.0 & $\mathbf{- 0 . 0 5}$ \\
\hline 4 & +0.0 & $<W T P^{a} \leq$ & +0.1 & $+\mathbf{0 . 0 5}$ \\
\hline 5 & +0.1 & $<W T P^{a} \leq$ & 0.5 & $+\mathbf{0 . 3}$ \\
\hline never & +0.5 & $<W T P^{a}$ & & $+\mathbf{0 . 5}$ \\
\hline
\end{tabular}

$\boldsymbol{W T P}^{d}$ for $W P T^{d}>0:\left|W T P^{d}\right|=$ amount of own material payoff the decision maker is willing to give up in the domain of disadvantageous inequality in order to increase the other's material payoff by one unit;

for $W P T^{d}<0:\left|W T P^{d}\right|=$ amount of own material payoff the decision maker is willing to give up in the domain of disadvantageous inequality in order to decrease the other's material payoff by one unit (in this interpretation inequalities need to be reversed; for instance, subjects who never switch on the $\mathrm{X}$-list reveal that they are willing to give up at least 50 Cents of their own income to decrease the income of the other player by 1 Euro);

$\boldsymbol{W T P}^{a}$ defined similarly for the domain of advantageous inequality. 